\title{
A atuação do Serviço Social junto a pacientes terminais: breves considerações ${ }^{*}$
}

Social Services' practices towards terminal patients: brief considerations

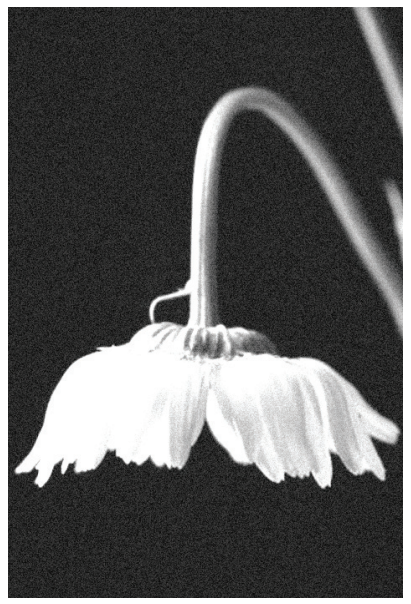

\author{
Andréa Branco Simão** \\ Fernanda dos Santos $* * \star$ \\ Liane de Freitas Oliveira ${ }^{* * *}$ \\ Renata Aline dos Santos ${ }^{* * *}$ \\ Rita Colen Hilário *** \\ Suélem Cabral Caetano ${ }^{* * *}$
}

Resumo: A forma de encarar a morte modificou-se ao longo do tempo e, atualmente, este acontecimento causa certo pavor. Esse sentimento de pavor pode se agravar no caso de pacientes terminais, pois, além de terem que enfrentar uma gama de dificuldades relativas à doença que possuem, passam a lidar constantemente com a questão da morte. Neste contexto, embora o papel do assistente social seja fundamental, ele ainda é pouco conhecido e as reflexões sobre as possibilidades e limites de atuação dos profissionais junto a pacientes terminais permanecem escassas. Diante disso, o objetivo deste artigo é trazer à tona algumas considerações sobre o papel do assistente social junto a esses indivíduos.

Palavras-chave: Morte. Paciente terminal. Serviço Social.

Abstract: The way to face death has changed over time, and currently this event causes fear, which may be worse in the case of terminal patients, because, besides having to face a range of difficulties

* Artigo produzido a partir das aulas de Oficina de Pesquisa I e Oficina de Pesquisa II, no curso de Serviço Social da Pontifícia Universidade Católica de Minas Gerais, Unidade de Contagem.

** Assistente social, mestre em Sociologia pela Texas A\&M University, doutora em Demografia pelo Centro de Desenvolvimento e Planejamento Regional (Cedeplar) da Universidade Federal de Minas Gerais, professora da Escola de Serviço Social da Pontifícia Universidade Católica de Minas Gerais — Unidade de Contagem — e assistente social/pesquisadora do Cedeplar/UFMG — Contagem, Brasil. E-mail: andrea-simao@ uol.com.br.

***Alunas do oitavo período do curso de Serviço Social da Pontifícia Universidade Católica de Minas Gerais - Unidade de Contagem/MG, Brasil. 
related to their diseases, they also have to deal constantly with the issue of death. In this context, although the role of a social worker is essential, it is still scarcely known, and the reflections on the possibilities and limits of the social worker's expertise with terminal patients remain rare. Considering that, the purpose of this paper is to bring to light some thoughts about the social worker's role with these individuals.

Keywords: Death. Terminal patient. Social Work.

\section{Introdução}

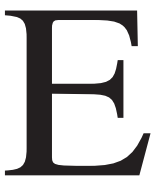

mbora as pessoas costumem dizer "que a morte faz parte da vida ou que desta vida a única coisa da qual se tem certeza é que vamos morrer", o desejo pela morte não é algo comum. Pelo contrário, em geral as pessoas

evitam falar sobre o assunto ou, quando o fazem, colocam a morte como algo ainda muito distante delas próprias. Este cenário muda quando surge algum tipo de doença mais prolongada e com poucas perspectivas de cura. Nesses casos, tanto a pessoa doente quanto seus familiares enfrentam diversas dificuldades, as quais incluem desde situações de medo, ansiedade, dúvidas, até longos e dolorosos processos de tratamentos. Diferentes profissionais podem atuar no sentido de amenizar estas e outras dificuldades que possam surgir, entre os quais estão o médico, o enfermeiro e o assistente social.

Considerando que a prática do assistente social nesta seara ainda é pouco explorada, o objetivo central aqui é desenvolver algumas reflexões sobre as possibilidades e limites da atuação deste profissional junto a pacientes terminais. Para tanto, este artigo está dividido em cinco partes, sendo a primeira esta introdução. Para contextualizar a discussão, a segunda parte aborda questões relacionadas à concepção histórica da morte e suas implicações na sociedade contemporânea. A terceira parte apresenta alguns aspectos relativos à condição do paciente terminal, os estágios que atravessa durante o processo de doença e os cuidados paliativos. A quarta parte levanta algumas questões relativas ao papel do assistente social junto ao paciente terminal e também junto à sua família. Por fim, a quinta parte apresenta algumas considerações finais elaboradas acerca do tema tratado.

\section{A morte e a sociedade contemporânea}

Ao longo dos tempos, o olhar do homem sobre a morte, tanto dele próprio quanto do outro, passou por diversas transformações. De acordo com Ariès (1981), 
na Idade Média, por exemplo, a morte era encarada como algo simples e, por esta razão, era aceita como sendo justa, natural e destino de todo ser vivo. No período que a antecedia, era importante que o moribundo estivesse rodeado pelos amigos e pela família, incluindo as crianças. Quando pressentia que havia chegado a sua hora, o moribundo pedia perdão para aqueles que o rodeavam e, assim, considerava-se preparado para morrer. Nesse período da história, embora o moribundo aguardasse a morte em seu leito, rodeado por entes queridos, ele era protagonista de sua própria morte, pois tomava as precauções necessárias para o seu fim, o qual se tornava um ato público. Quanto a esta questão, Ariès esclarece que:

A câmara do moribundo convertia-se então em lugar público. A entrada era livre... Os transeuntes que encontravam na rua o pequeno cortejo do sacerdote com o viático acompanhavam-no e entravam atrás dele no quarto do doente. (1981, p. 24)

No período que engloba os séculos XVI a XVIII o fenômeno da morte é marcado por uma nova característica. Segundo Ariès (1981), nesse tempo o homem começou a pensar na morte do outro. Essa mudança em relação à morte acontece, de acordo com o autor, em virtude das transformações que ocorrem na concepção de família, a qual passa a ser muito mais fundada no afeto. Neste sentido, a morte passa a ser vista como uma violação que arranca o outro do convívio familiar de forma abrupta e repentina.

Durante o século XIX a morte é vista como uma transgressão ao afeto e à união ao tirar o homem de sua vida cotidiana. Nessa fase, gerava sentimentos de melancolia. O sentimento de morte como fracasso ainda não era uma característica desse período. Somente em meados do século XX é que a eminência da morte passa a ser vista como algo que deve ser escondido enquanto for possível. Sobre isto Ariès coloca que:

O círculo de relações do moribundo tende a poupá-lo, escondendo a gravidade do seu estado; admite-se, porém, que a dissimulação não pode durar muito tempo e o doente acaba por saber, mas nesse caso os parentes não têm já a coragem cruel de serem eles mesmos a dizer a verdade. $(1981$, p. 55)

É nessa fase que, a partir da intolerância à morte do outro, a morte passa a ser estigmatizada. À medida que se procura, a todo custo, a cura para a doença, a proximidade da morte deve ser escondida até o fim. Além disto, diferentemente dos 
períodos anteriores, morrer em casa deve ser evitado tanto quanto possível. Os centros médicos passam a ser encarados como os locais mais apropriados para isso, pois é neles que se luta contra o fim por meio de cuidados especializados. Nesse contexto, a morte passa a ser um fenômeno técnico, confirmada pela parada dos sentidos e pela impossibilidade de ação médica. A equipe hospitalar assume papéis outrora desempenhados pelo próprio moribundo e/ou por sua família. Ariès ilustra o que acontece entre as décadas de 1930 e 1950 com as seguintes palavras: "Já não se morre em casa, no meio dos seus, morre-se no hospital, e só. Porque é no hospital que se proporcionam cuidados que já não são viáveis em casa. É no centro médico que se luta contra a morte" (1981, p. 56).

Assim, a partir da década de 1950 a morte passa para os domínios das Unidades de Terapia Intensiva (UTI), tornando-se asséptica e invisível. O homem moderno evita falar no assunto e vive como se jamais fosse morrer. Este sentimento pode estar aliado ao fato de que, hoje, morrer é encarado como algo solitário, triste, mecânico e desumano. Diferentemente do que ocorria no passado, na atualidade a morte deve ocorrer fora do ambiente familiar. As crianças e mesmo alguns adultos não devem acompanhar esse processo, considerado extremamente traumático. Além disso, nos casos de doenças terminais em geral, o doente não decide sobre sua hospitalização. Neste contexto, a família passa a ter um papel fundamental.

\section{0 paciente terminal: estágios e cuidados paliativos}

Em 1969, o estudo On death and dying (Sobre a morte e o morrer), realizado pela psiquiatra norte-americana Kübler-Ross, causou grande impacto na área dos cuidados de saúde ao apresentar uma reflexão sobre os processos de negação, raiva, barganha, depressão e aceitação, considerados estágios pelos quais as pessoas passam quando estão na fase final de vida.

Segundo Kübler-Ross, o primeiro estágio, denominado da negação, aparece na maioria dos doentes terminais e é comum, também, em pacientes que são informados de maneira abrupta, prematura ou leviana sobre sua condição. A negação, de acordo com a autora, funciona como um para-choque, uma defesa temporária que, em seguida, é substituída pela aceitação parcial.

A raiva é o estágio que vem após a negação. Ela acontece, fundamentalmente, contra a equipe médica, contra a família e até contra a religião. Quando está 
vivenciando essa etapa, o doente fala mal de tudo e de todos, queixa-se constantemente e procura chamar a atenção daqueles que o rodeiam com mensagens que indicam que as pessoas não devem se esquecer de que ele ainda está vivo. Além disso, nessa etapa, alguns pacientes terminais agem como se pudessem comprar sua saúde, o que, em geral, torna o processo ainda mais doloroso.

A tentativa de negociar o estado de saúde é um comportamento que faz parte do terceiro estágio, definido como a barganha. Nessa fase, o paciente terminal tenta trocar com Deus, com o mundo ou com a religião o bom comportamento pelo prolongamento da vida ou, simplesmente, por alguns dias sem ter que enfrentar a dor física.

A depressão, característica do quarto estágio, acontece quando a negação, raiva e a barganha cedem lugar a um sentimento grande de perda. Nessa fase, tudo perde a razão de ser: a família, o trabalho e os amigos não são mais encarados como importantes, pois o paciente sente que está prestes a perder tudo e todos que ama.

O último estágio, definido como sendo o da aceitação, é aquele no qual o paciente, já tendo passado por todos os outros estágios, para de lutar, de ter raiva, de barganhar. Fisicamente ele sente-se mais debilitado, mostrando desejo de ficar sozinho e de dormir por mais tempo. Apesar disso, emocionalmente, ele se sente melhor. Pacientes terminais que atravessam períodos mais longos de negação são os que apresentam mais dificuldade para chegar ao estágio de aceitação. Os pacientes que passam mais facilmente por todos os estágios são aqueles encorajados a extravasar a raiva, chorar ou falar de seus sentimentos.

Ao tratar dos diferentes estágios vivenciados pelo paciente terminal, Kübler-Ross (1981) também desenvolve algumas considerações sobre o papel da família no processo da morte. Um dos argumentos é de que, em geral, a família não sabe como lidar com a morte. Neste sentido, a autora ressalta que, ao receber a notícia da provável morte de um ente querido, a reação manifesta pela família tanto pode contribuir para que o mesmo se revolte ou aceite sua condição. Quanto a isso, ela coloca que:

Se não levarmos em conta a família do paciente terminal, não poderemos ajudá-lo com eficácia, os familiares desempenham um papel preponderante, e suas reações muito contribuem para a própria reação do paciente. (Kübler-Ross, 1981, p. 163)

Nesse contexto, cabe à equipe de profissionais que atua junto a pacientes terminais contribuir para que as famílias e os pacientes compartilhem seus senti- 
mentos uns com os outros e fortaleçam os laços que existem entre eles. Em geral, há uma tendência de afastamento, pois, de um lado, o paciente não quer incomodar a família e, de outro, a família não quer acompanhar o paciente para que ele não sinta que seu fim está próximo. Tal situação gera ansiedade, dúvidas e normalmente faz com que a família se sinta muitas vezes culpada por não poder fazer algo para salvar o outro.

Nos anos de 1990 surgem formas alternativas para amparar não só o paciente como também sua família. Uma delas, talvez a que mais tem crescido ao longo dos anos em todo o mundo, é a que envolve cuidados paliativos, ou seja, a denominada medicina paliativa. Esta nova abordagem do paciente terminal e de sua família nasceu da necessidade de melhorar a qualidade de vida dos pacientes para os quais a cura não é mais possível. Segundo a Organização Mundial da Saúde (OMS), em 1990, cuidado paliativo podia ser definido da seguinte forma:

O cuidado ativo total de pacientes cuja doença não responde mais ao tratamento curativo. Controle da dor e de outros sintomas e problemas de ordem psicológica, social e espiritual são prioritários. O objetivo dos cuidados paliativos é proporcionar a melhor qualidade de vida para os pacientes e seus familiares

Alguns anos após, mais precisamente em 2002, a OMS reviu e ampliou tal conceito, enfatizando não somente a questão da qualidade de vida, mas também a questão da prevenção do sofrimento. Nessa nova versão, cuidado paliativo passou a ser definido como

uma abordagem que aprimora a qualidade de vida, dos pacientes e famílias que enfrentam problemas associados com doenças ameaçadoras de vida, através da prevenção e alívio do sofrimento, por meios de identificação precoce, avaliação correta e tratamento da dor e outros problemas de ordem física, psicossocial e espiritual.

Os cuidados paliativos não prolongam a vida, nem tampouco aceleram a morte. Na verdade, eles são implementados para atender, de forma mais humanizada possível, ao paciente e à sua família. Os profissionais que adotam essa postura procuram estar presentes nas diferentes fases do processo de doença e dando não somente suporte físico, mas também assistência emocional, social e espiritual durante a fase terminal e de agonia do paciente. Além disso, esses profissionais também procuram auxiliar a família e os amigos a lidar com a questão. Nesse cenário 
emerge a questão: quais as possibilidades de atuação do assistente social junto aos pacientes terminais e seus familiares?

\section{0 assistente social na saúde e sua atuação junto ao paciente terminal}

No Brasil, a busca pela ampliação e garantia dos direitos relativos aos serviços e ações de saúde é um movimento contínuo e que vem se fortalecendo desde a Constituição Federal e a implantação do Sistema Único de Saúde, em 1988. A partir dessa época, uma série de exigências vem se colocando aos setores da comunidade científica e profissional que se dedicam às questões relacionadas com a saúde. Uma delas diz respeito à forma de abordar as questões relativas à saúde, a qual deve levar em conta não somente aspectos físicos dos indivíduos, mas também fatores socioeconômicos, culturais e ambientais que influenciam e determinam as condições de vida e saúde dos mesmos. Saúde não significa apenas a ausência de doença. Nogueira e Mioto (2006), citando Cecílio, afirmam que os fatores que determinam a saúde podem ser divididos em quatro conjuntos, a seguir explicados:

O primeiro são as boas condições de vida, entendendo-se que o modo como se vive se traduz em diferentes necessidades. $\mathrm{O}$ segundo diz respeito ao acesso às grandes tecnologias que melhoram ou prolongam a vida. É importante destacar que, nesse caso, o valor do uso de cada tecnologia é determinado pela necessidade de cada pessoa, em cada momento. $\mathrm{O}$ terceiro bloco refere-se à criação de vínculos efetivos entre usuários e o profissional ou equipe dos sistemas de saúdes. Vínculos devem ser entendidos, nesse contexto, como uma relação contínua, pessoal e calorosa. Por fim, necessidades de saúde estão ligadas também aos graus de crescente autonomia que cada pessoa tem no seu modo de conduzir a vida, o que vai além da informação e da educação. (p. 12)

Nesse contexto, Nogueira e Mioto ressaltam que não é possível compreender ou definir as necessidades de saúde sem levar em conta que elas são produzidas nas relações sociais que se estabelecem dentro de um ambiente físico, social e cultural. Nessa perspectiva, se instituem as ações dos assistentes sociais, as quais devem estar voltadas para a promoção da qualidade de vida tanto em situações em que a saúde prevalece como naquelas em que os processos de doença se instalam.

Como profissão, historicamente o Serviço Social tem sua atenção voltada para a compreensão da questão social. Em sua trajetória, os profissionais da área têm participado e trabalhado no debate das alternativas de enfrentamento de tais questões, 
buscando, no âmbito da saúde, atuar de acordo tanto com os princípios discutidos e preconizados pelos defensores da reforma sanitária como pelos dispostos no Código de Ética que rege a profissão. Neste sentido, Nogueira e Mioto (2006, p. 12-13) ressaltam o seguinte:

Como se vê, a definição de necessidades de saúde ultrapassa o nível de acesso a serviços e tratamentos médicos, levando em conta as transformações societárias vividas ao longo do século XX e já no XXI, com a emergência do consumismo exacerbado, a ampliação da miséria e da degradação social e das perversas formas de inserção de parcelas da população no mundo do trabalho. Mais que isso, envolve aspectos éticos relacionados ao direito à vida e à saúde, direitos e deveres. Nesse sentido, é necessário apreender a saúde como produto e parte do estilo de vida e das condições de existência, sendo que a situação saúde/doença é uma representação da inserção humana na sociedade.

É importante destacar também que a área da saúde tem, historicamente, concentrado um grande número de assistentes sociais De acordo com Bravo et al. (2007), a partir dos anos 1990, com a implementação da gestão descentralizada da saúde, há uma ampliação da contratação de profissionais do Serviço Social na área. Nesse período, a demanda por esse profissional aumenta em decorrência da utilidade do mesmo para o atendimento das questões cotidianas envolvendo situações relacionadas com a saúde dos indivíduos. Neste sentido, Costa (2000), citando Netto, afirma que:

Um mercado não se estrutura para o agente profissional mediante as transformações ocorrentes no interior do seu referencial ou no marco de sua prática, antes, estas transformações expressam exatamente a estruturação do mercado de trabalho, posto que uma profissão não se constitui para criar um dado espaço na rede sócio-ocupacional, mas é a existência deste espaço que leva à constituição profissional. (2000, p. 36)

O mercado de trabalho dos assistentes sociais na área de saúde vem crescendo. Especificamente nos hospitais, esses profissionais são requisitados para o desenvolvimento de diversas atividades, dentre as quais Costa (2000) destaca as seguintes:

Em geral o assistente social é responsável pela sensibilização e mobilização dos usuários nas situações relativas à captação de sangue, realização de exames complexos, tratamento fora do domicílio, necropsias, superação de preconceitos/tabus em 
relação ao tratamento da doença etc. Além destas, são de responsabilidade do assistente social as comunicações em geral. No caso dos hospitais, essas comunicações referem-se a altas, óbitos e/ou estados de saúde do "paciente", nos centros de saúde e ambulatórios especializados, o assistente social concentra-se nas comunicações sobre resultados de exames, particularmente aqueles que indicam sério comprometimento do estado de saúde, ou doenças transmissíveis, como é o caso da Aids, ou, ainda, de doenças crônico-degenerativas, como é o caso das neoplasias, leucemias etc. (Bravo, 2000, p. 52-53)

Cabe aos assistentes sociais, de acordo com Bravo e Matos (Bravo et al., 2007, p. 43), "formular estratégias que busquem reforçar ou criar experiências nos serviços que efetivem o direito social à saúde, em uma ação articulada com outros profissionais que defendam o aprofundamento do Sistema Único de Saúde". O assistente social deve, ainda, se mostrar disponível ao paciente e aos seus familiares, buscando conhecer suas reais necessidades e procurando assegurar os direitos e benefícios dos mesmos. Nesta direção, Nogueira e Mioto (2006, p. 8) comentam o seguinte:

Nesta acepção, fica evidente que a integralidade não é atributo específico de uma determinada profissão nem de um serviço, mas compreende distintas práticas profissionais interdisciplinares que se articulam no campo da promoção da saúde, através de diferentes serviços e instituições.

Nesse cenário, é possível argumentar que não cabe somente ao assistente social integrar as equipes que tratam de pacientes terminais, mas também se preparar para a realização deste trabalho que é permeado por inúmeros desafios. Um dos primeiros a ser enfrentado pelos profissionais que ingressam nessa seara está na bagagem de conhecimentos adquiridos durante a vida acadêmica. É fato que, ao longo do curso, poucos são os espaços que permitem que o estudante se torne preparado para tratar das questões relacionadas às doenças terminais e à morte. Apesar desta lacuna, é possível dizer que, de maneira geral, a formação dada aos alunos permite que os mesmos desenvolvam uma capacidade de escuta e de entendimento de questões objetivas e subjetivas envolvidas nas situações que atendem. Este fato abre possibilidades para que o assistente social seja um profissional participativo e criativo e que pode construir propostas para atender às necessidades dos indivíduos com algum tipo de demanda na saúde.

No caso dos pacientes terminais, o profissional do Serviço Social tem a possibilidade de atuar na direção dos cuidados paliativos. Dessa forma, diante de um 
quadro de doença terminal, o assistente social deveria ser capaz de, junto com outros profissionais, aprimorar a qualidade de vida do paciente, oferecendo ao mesmo e a sua família suporte emocional e social. Ouvir o paciente e também o seu familiar poderia ser o ponto de partida para os profissionais da área que atuam junto a pacientes terminais dentro da abordagem que se denomina como cuidados paliativos. Neste sentido, a preocupação destes profissionais deve ir muito além daquelas relacionadas com os aspectos externos e biológicos da doença, voltando-se, também, para as dimensões psicossociais e espirituais que permeiam o paciente que possui uma doença terminal. De acordo com Ballone (2003), o profissional que adota o método paliativo vai atuar não só respeitando as vontades do mesmo, mas também seus sentimentos. Neste sentido, o autor ressalta que:

É nessa fase, a paliativa, que a autonomia do paciente deve adquirir maior relevância e autoridade na tomada de decisões. Para tal, é fundamental que o médico e a família tenham plena noção do curso da doença, da fase em que se encontra e do que, realmente, está ao alcance da medicina sem sacrificar a já precária qualidade de vida do paciente. (p. 2)

Assim, na prática, o assistente social, junto com os demais profissionais, deve fortalecer o sistema de apoio ao paciente, evitando que o mesmo tenha de enfrentar situações que gerem sentimentos como abandono, limitação, dependências etc. Enfim, em conjunto com outros profissionais, o assistente social deve agir de forma a contribuir para que esse paciente se sinta respeitado, valorizado e amado. Além disso, em diversos casos o profissional pode auxiliar no resgate da dignidade que, muitas vezes, se perde com a descoberta da doença e a impossibilidade de cura. Tal dignidade é resgatada a partir de pequenos gestos, tanto por parte da família quanto da equipe responsável pelos cuidados com o paciente. Entre tais gestos estão a escuta da vontade dele e a busca de compreensão da mesma. Sobre esse aspecto, Kubler-Ross (1981) considera que:

Seus desejos e opiniões deveriam ser respeitados, eles mesmos deveriam ser ouvidos e consultados. Se seus anseios são contrários às nossas crenças e convicções no que tange a cirurgias futuras ou tratamentos, deveríamos falar abertamente deste conflito e deixar que o paciente tome a decisão. (p. 182)

Diante do exposto, é possível argumentar que, embora a formação acadêmica não ofereça todos os requisitos necessários para a atuação do assistente social 
junto a pacientes terminais, esse profissional, pelas outras habilidades que desenvolve ao longo de sua formação e vida profissional, pode contribuir para aprimorar a qualidade de vida dos mesmos, pois detém um saber que é imprescindível na atenção ao paciente e à sua família: a capacidade de escuta e de leitura da realidade social.

\section{Considerações finais}

Ao longo da história, os avanços na medicina tiveram várias consequências, entre as quais está o aumento do controle sobre os processos de doença e, por conseguinte, sobre o prolongamento da vida. Apesar disto, ainda existem inúmeras dificuldades para lidar com as situações que envolvem doenças terminais.

As doenças terminais envolvem, em geral, situações de stress, em que o sofrimento físico e o emocional se misturam e causam várias dificuldades e desafios para aqueles que vivenciam o processo. Embora os avanços tecnológicos na área médica permitam que muitas das dificuldades de uma doença terminal sejam minimizadas, algumas questões necessitam de cuidados que vão além do que a parte física do indivíduo precisa. Como apontado ao longo do estudo, o doente terminal, ao lidar com sua situação, passa por vários estágios, e sua família muitas vezes não sabe como lidar com os mesmos, piorando um quadro que já não é fácil de ser trabalhado. Nesse ponto, é possível pensar no papel do assistente social e na proposta denominada como cuidados paliativos, pois, apesar da evolução nos tratamentos e do aumento no número de profissionais envolvidos nos cuidados com pacientes terminais, ainda há uma carência na atenção ao mesmo e à sua família.

Em virtude do exposto, é importante lembrar que Moritz (2002) enfatizou o papel da equipe hospitalar, apontando que é essencial que os profissionais que a integram detenham conhecimentos e capacidade para analisar as situações e os contextos envolvendo os pacientes terminais e suas famílias. Isto tudo deve acontecer dentro de um ambiente de muito diálogo e de troca de informações, para que o trabalho desenvolvido atinja de forma eficiente e eficaz os resultados desejados na humanização e no cuidado de cada paciente.

Nesse sentido, a proposta de cuidados paliativos é fundamental e precisa ser conhecida pelos assistentes sociais. É uma das poucas propostas que permite o desenvolvimento de um trabalho que une os profissionais, o paciente e a família na 
busca de alternativas para minimizar o sofrimento e possibilitar promoção da qualidade de vida de pacientes que se encontram diante de uma doença terminal.

Entre os vários desafios que permeiam a profissão na atualidade está a necessidade de contribuir para a construção e a objetivação de políticas sociais mais justas. Desse modo, a compreensão sobre as necessidades que vêm surgindo na área de saúde fazem parte da possibilidade de intervenção e atuação do assistente social. Nota-se uma carência muito grande nesse setor, o que constitui um desafio, porém não um limite para o profissional que é engajado e comprometido. Nesse sentido, espera-se que este artigo possa contribuir para o conhecimento e a reflexão da categoria diante das diversas demandas sociais, além de propor uma articulação entre saber e prática no atendimento ao paciente terminal.

Artigo recebido em out./2009 - Aprovado em mar./2010

\section{Referências bibliográficas}

ARIÈS, Philippe. Sobre a história da morte no Ocidente desde a Idade Média. Lisboa: Teorema, 1981.

BALLONE G. J. Medicina paliativa e qualidade de vida. Disponível em: <http:// gballone.sites.uol.com.br/psicossomatica/paliativa.html>. Acesso em: 2003.

BRASIL. Congresso Nacional. Constituição da República Federativa do Brasil. Brasília, 1988.

Lei n. 8.080, de 19 de setembro de 1990. Dispõe sobre as condições para a promoção, proteção e recuperação da saúde; a organização e o funcionamento dos serviços correspondentes e dá outras providências. Brasília, 1990.

. Ministério da Saúde. Cuidados paliativos oncológicos: controle de sintomas. Rio de Janeiro: Inca, 2001. Disponível em: <http://bvsms.saude.gov.br/bvs/publicacoes/inca/manual_cuidados_oncologicos.pdf $>$. Acesso em: 16 ago. 2008.

BRAVO, Maria Inês Souza et al. (Org.). Saúde e Serviço Social. São Paulo: Cortez, 2007.

BRUM, Eliane. A enfermaria entre a vida e a morte. Devemos prolongar a vida ou aceitar o fim? Época, São Paulo, n. 539, p. 56-60, 2008. 
COHN, Amélia. Medicina social - a reforma sanitária brasileira: a vitória sobre o modelo neoliberal. Sección Especial: Reformas Progresistas en Salud. Disponível em: $<$ www.medicinasocial.info $>$. Acesso em: 3 nov. 2008.

COSTA, Maria Dalva Horácio da. O trabalho nos serviços de saúde e a inserção dos(as) assistentes sociais. Serviço Social \& Sociedade, São Paulo, ano XXI, n. 62, mar. 2000.

KLÜBER-ROSS, E. Sobre a morte e o morrer. São Paulo: Martins Fontes, 1981.

MINAYO, M. C. S. O desafio do conhecimento: pesquisa qualitativa em saúde. São Paulo: Hucitec; Rio de Janeiro: Abrasco, 1999.

(Org.). Pesquisa social: teoria, método e criatividade. 13. ed. Petrópolis: Vozes, 1999.

MORITZ, Raquel Duarte. O efeito da informação sobre o comportamento dos profissionais de saúde diante da morte. 2002. Tese (Doutorado em Engenharia de Produção) — Universidade Federal de Santa Catarina, Florianópolis.

NOGUEIRA, V. M. R.; MIOTO, R. C. T. Desafios atuais do Sistema Único de Saúde — SUS e as exigências para os assistentes sociais. In: MOTA, E. E. et al. (Org.). Serviço Social e saúde: formação e trabalho profissional. São Paulo: Cortez, 2006. v. 1, p. 218-241.

PESSINI, Leo. Cuidados paliativos. Alguns aspectos conceituais, biográficos e éticos. Prática Hospitalar, Rio de Janeiro, ano VII, n. 41, set./out. 2005.

SILVA, Ronaldo Corrêa Ferreira da; HORTALE, Virginia Afonso. Cuidados paliativos oncológicos: elementos para o debate de diretrizes nesta área. Caderno de Saúde Pública, Rio de Janeiro, out. 2006. 